\title{
A Comparative Assessment of Peri-implant Soft and Hard Tissues with Immediate and Delayed Implants
}

\author{
Srinivasan Bhuvaneshwari ${ }^{1}$, Priyaranjann ${ }^{2}$, Singh Jyotirmay ${ }^{3}$, Baburajan Kandasamy ${ }^{4}$, Sumit Dash ${ }^{5}$, Mohammed A Razi ${ }^{6}$
}

\begin{abstract}
Aim and objective: This study was done to assess peri-implant soft tissues and hard tissues in immediate and delayed titanium implants cases. Materials and methods: This study was conducted on 84 patients who were randomly divided into two groups. Group I was immediate implant group (42 patients) and group II was delayed implant group (42 patients). Parameters such as peri-implant esthetic score, crestal bone defect, and densitometry of peri-implant were evaluated after 1 week, 1 month, 3 months, and 6 months.

Results: The mean peri-implant esthetic score at first week in group I was 7.4 and in group II was 5.8, at first month in group I was 6.8 and in group II was 4.6, at third month in group I was 6.7 and in group II was 4.5 and at sixth month in group I was 6.4 and in group II was 4.4 . The difference was significant ( $p$ value $<0.05$ ). The mean peri-implant crestal bone loss $(\mathrm{mm})$ after 1 week, 1 month, 3 months, and 6 months in group I was $0.24,0.64,0.86$, and 1.04 and in group II was $0.28,0.70,0.94$, and 1.14 , respectively. The difference was nonsignificant ( $p$ value $>$ 0.05). The mean peri-implant bone densitometry after 1 week, 1 month, 3 months, and 6 months in group I was 52.4, 45.6, 42.4, and 40.2 and in group II was $64.2,60.5,55.2$, and 47.6 , respectively. The difference was significant ( $p$ value $<0.05$ ).

Conclusion: Instantaneous implants exhibited enhanced esthetic and purposeful result such as healing of peri-implant bone and peri-implant soft tissues when compared to delayed implants.

Clinical significance: Immediate implants can be used to improve esthetic and determined result in healing of peri-implant bone and periimplant soft tissues.
\end{abstract}

Keywords: Bone loss, Delayed implants, Immediate implants.

The Journal of Contemporary Dental Practice (2020): 10.5005/jp-journals-10024-2911

\section{INTRODUCTION}

Dental implants are the best invention in the field of dentistry for replacing missing teeth. A good-quality bone allows better anchorage of dental implant. ${ }^{1}$ Dental implant insertion in wellhealed socket ensures success rate. ${ }^{2}$ Sufficient bone maturation following tooth extraction minimizes the risk of infection, ensures steady base for the implant, and enhances the width of keratinized part of gingiva. ${ }^{3}$

Short treatment procedure is always desirable. This allows patients to restore function and to maintain the soft and hard tissue. Immediate dental implants are inserted immediately following tooth extraction. ${ }^{4}$ Delayed implants are inserted after 3 months of extraction, and staged implants are inserted 8 weeks after extraction. The insertion of dental implants is based on timing of placement. ${ }^{5}$ According to Gomez-Roman et al., ${ }^{6}$ implant insertion from zero to 7 days following tooth extraction is called immediate implants.

Hämmerle et al. ${ }^{7}$ suggested new classification of dental implants according to timing of insertion. They proposed type I implant as immediate placement in which dental implant is instantly placed as part of the same procedure following tooth extraction without bone or soft tissues healing. Type II was early implant position, where a healing period of $4-8$ weeks is considered, and during this, there is partial healing of socket with soft tissue coverage of the alveolus. Type III was early placement in which a healing period of $12-16$ weeks is given, and there is significant healing of socket with sufficient soft tissue coverage. Type IV was late placement in which a healing period of 6 months is given, and during this period there is fully healed edentulous site.
${ }^{1}$ Department of Oral Medicine and Radiology, Kalinga Institute of Dental Sciences, KIIT University, Bhubaneswar, Odisha, India

${ }^{2}$ Department of Public Health Dentistry, Kalinga Institute of Dental Sciences, KIIT University, Bhubaneswar, Orissa, India

${ }^{3}$ Department of Orthodontics and Dentofacial Orthopedics, Patna Dental College and Hospital, Patna, Bihar, India

${ }^{4}$ Department of Prosthodontics, RVS Dental College and Hospital, Coimbatore, Tamil Nadu, India

${ }^{5}$ Department of Conservative Dentistry and Endodontics, Institute of Dental Science, Siksha O' Anusandhan, Deemed to be University, Bhubaneswar, Odisha, India

${ }^{6}$ Department of Periodontology, Hazaribag College of Dental Sciences and Hospital, Hazaribag, Jharkand, India

Corresponding Author: Singh Jyotirmay, Department of Orthodontics and Dentofacial Orthopedics, Patna Dental College and Hospital, Patna, Bihar, India, Phone: +919334115000, e-mail: drjyothirmaysingh@ gmail.com

How to cite this article: Bhuvaneshwari S, Priyaranjan, Singh J, et al. A Comparative Assessment of Peri-implant Soft and Hard Tissues with Immediate and Delayed Implants. J Contemp Dent Pract 2020; 21(11):1249-1252.

Source of support: Nil

Conflict of interest: None

With the advent of immediate implants, treatment period and number of surgical procedures have diminished significantly. ${ }^{8}$ Factors such as steady support of bone, limited amount of inflammation, and practical implant sustained crowns are

() Jaypee Brothers Medical Publishers. 2020 Open Access This article is distributed under the terms of the Creative Commons Attribution 4.0 International License (https://creativecommons.org/licenses/by-nc/4.0/), which permits unrestricted use, distribution, and non-commercial reproduction in any medium, provided you give appropriate credit to the original author(s) and the source, provide a link to the Creative Commons license, and indicate if changes were made. The Creative Commons Public Domain Dedication waiver (http://creativecommons.org/publicdomain/zero/1.0/) applies to the data made available in this article, unless otherwise stated. 
considered to be successful dental implant therapy. It is evident that within first year of implant insertion, there is maximum bone loss around the implant. Peri-implant mucosa and esthetic outcome can be affected by marginal peri-implant bone failure. ${ }^{9}$ The present study was conducted to assess soft and hard tissues of peri-implant in immediate and delayed titanium implants cases.

\section{Materials and Methods}

The study was done form March 2017 to November 2018 by two trained investigators in Department of Prosthodontics, Uttaranchal Dental and Medical Research Institute, Dehradun. This study was conducted on 84 patients who comprised of 40 males and 44 females in the age range 18-40 years who visited to the department of prosthodontics. There were total of 112 implant sites. The study commenced after obtaining ethical clearance from ethics committee, and consent from all patients was taken. The inclusion criteria were patients within specified age-group with missing teeth in maxillary esthetic zone. Exclusion criteria were patients' aged above 40 years, alcoholics, smokers, patients with periodontitis, and those who were not willing to participate in the study.

Patients were randomly divided into two groups based on lottery system. Group I was immediate implant group (42 patients) and group II was delayed implant group (42 patients). Two trained dentists performed all the procedures using titanium dental implants of $\mathrm{GMI}^{\oplus}$ frontier grade IV. In group I, a thorough clinical and radiographical assessment was done, and dental implants were inserted immediately following tooth extraction after following all standardized parameters.

In group II, patients with 8 week history of extraction were subjected to radiovisiography (RVG) of the site. Based on radiographic findings, bone height and width were measured, and titanium dental implants were inserted. Following implant placement, passive repositioning of mucoperiosteal flaps was done using 4-0 silk suture. All participants were put on Cap. Amoxicillin $500 \mathrm{mg} \times \mathrm{TDS} /$ day, anti-inflammatory diclofenac $50 \mathrm{mg}$ TDS/ day, and $0.2 \%$ chlorhexidine mouthwash for 5 days. One week postoperatively, sutures were removed.

Participants were assessed postoperatively for soft tissue and hard tissue factors after 1 week, 1 month, 3 months, and 6 months. Estimation of implant esthetic score with respect to peri-implant soft tissue, and radiographic evaluation of crestal bone defect and densitometry of peri-implant was considered.

In all the cases, implant esthetic scoring was used for periimplant soft tissue evaluation. Esthetic scoring used in this study was based on Testori classification; ${ }^{10}$ the mesiodistal stability of papilla, peri-implant soft tissue texture, peri-implant soft tissue color, buccopalatal ridge stability, and gingival contour were calculated. In respect to stability of the mesiodistal papilla: score 0 mentioned for no papilla, score 1 mentioned when papilla does not occupy the complete space, but it is esthetically satisfactory in agreement with neighboring teeth, and score 2 indicated total fill of papilla. The vertical measurement from the apex of the distal and mesial part of papilla to the imaginary line relating the cementoenamel connection of the two adjoining teeth was considered as the dimensional stability of the papilla. The stature of the mesial and distal papilla was sporadically deliberate with respect to this line. Ridge constancy in buccopalatal direction was measured as $0=$ width with ridge loss and $1=$ width maintained ridge constancy. This was calculated as buccal bone resorption with reference to adjoining natural teeth from the first follow-up to the sixth month follow-up visit. With respect to texture of the soft tissues of peri-implant, score 0 indicated complete loss of texture, score 1 when inadequate healthy tissue with presence of some texture, and score 2 when healthy gingival tissue surrounding the natural teeth appears. Based on color of the peri-implant soft tissue, score 0 was indicative of completely dissimilar in color from healthy tissue, $1=$ does not appears as healthy tissue but still esthetically satisfactory, and $2=$ appears as healthy gingival tissue surrounding the natural teeth. Gingival contour was measured as obvious asymmetry from the established criteria of scalloping (score 0 ), signs of asymmetry but esthetically suitable (score 1) and harmonious gingival contour (score 2).

Crestal bone loss was measured using RVGs of the implant at follow-up visit after 1 week, 1 month, 3 months, and 6 months. Images were noted on a gray scale for the peri-implant bone gray scale assessment using Photoshop 10. The optical density curves were regulated to a proportion of grayscale in which the most radiopaque point represented the dense implant core, and digital number zero was given to it, and the most radiolucent point represented air and number 100 was given to it. Values were taken with distance from fourth to sixth threads of the implant body, and average values were regarded as final score. Mean values of both the investigators were used for statistical analysis. Results were statistically studied using SPSS version 21.0 after entering data in MS excel sheet. Paired and Unpaired $t$ test was used for comparison between both the groups.

\section{Results}

Table 1 shows there were 21 males and 20 females in group I and 18 males and 23 females in group II. Table 2 shows that mean peri-implant esthetic score at first week in group I was 7.4 and in group II was 5.8, at first month in group I was 6.8 and in group II was 4.6, at third month in group I was 6.7 and in group II was 4.5 and at sixth month in group I was 6.4 and in group II was 4.4. The difference was significant ( $p$ value $<0.05$ ). Table 3 shows that mean peri-implant crestal bone loss $(\mathrm{mm})$ after 1 week, 1 month, 3 months, and 6 months in group I was $0.24,0.64,0.86$, and 1.04 and in group II was $0.28,0.70,0.94$, and 1.14 , respectively. The difference was nonsignificant ( $p$ value $>0.05$ ). Table 4 shows that mean periimplant bone densitometry after 1 week, 1 month, 3 months, and 6 months in group I was 52.4, 45.6, 42.4, and 40.2 and in group II was $64.2,60.5,55.2$, and 47.6 , respectively. The difference was significant ( $p$ value $<0.05$ )

Table 1: Distribution of patients

\begin{tabular}{lll}
\hline Groups & Group I & Group II \\
\hline Implant group & Immediate implant & Delayed implant \\
Male & 22 & 18 \\
Female & 20 & 24 \\
\hline
\end{tabular}

Table 2: Assessment of peri-implant esthetic score

\begin{tabular}{llll}
\hline Time & Group I & Group II & p value \\
\hline 1st week & 7.4 & 5.8 & 0.01 \\
1st month & 6.8 & 4.6 & 0.01 \\
3rd month & 6.7 & 4.5 & 0.01 \\
6th month & 6.4 & 4.4 & 0.02 \\
\hline
\end{tabular}

$p<0.05$ 
Table 3: Assessment of peri-implant crestal bone loss

\begin{tabular}{lllllll}
\hline & \multicolumn{2}{c}{ Group I } & & \multicolumn{2}{c}{ Group II } \\
\cline { 2 - 3 } Time & Mean & SD & & Mean & SD & p value \\
\hline 1st week & 0.24 & 0.08 & & 0.28 & 0.07 & 0.81 \\
1st month & 0.64 & 0.14 & & 0.70 & 0.17 & 0.72 \\
3rd month & 0.86 & 0.18 & & 0.94 & 0.21 & 0.84 \\
6th month & 1.04 & 0.22 & & 1.14 & 0.30 & 0.91 \\
\hline
\end{tabular}

Unpaired $t$ test, $p<0.05$, significant

Table 4: Assessment of peri-implant bone densitometry

\begin{tabular}{lllllll}
\hline & \multicolumn{2}{c}{ Group I } & & \multicolumn{3}{c}{ Group II } \\
\cline { 2 - 3 } Time & Mean & $S D$ & & Mean & SD & pvalue \\
\hline 1st week & 52.4 & 3.12 & 64.2 & & 6.16 & 0.01 \\
1st month & 45.6 & 5.24 & 60.5 & 5.20 & 0.02 \\
3rd month & 42.4 & 6.32 & & 55.2 & 6.12 & 0.01 \\
6th month & 40.2 & 6.74 & & 47.6 & 6.17 & 0.01 \\
\hline
\end{tabular}

Unpaired $t$ test, $p<0.05$, significant

\section{Discussion}

Dental implants are routinely performed procedure, and the success of treatment depends on factors, such as amount of bone available, location, skill of operator, and gingival health. ${ }^{10}$ The peri-implant soft tissue supposed to be healthy and in synchronization with the adjoining teeth mucosa. Interimplant papillae height should be adequate for complete closure of area; however, inadequate interimplant papilla may lead to incomplete closure, thus affecting the esthetics. ${ }^{11}$ In the present study, soft and hard tissues of periimplant area in immediate and delayed titanium implants cases were assessed.

In the present study, we recruited 84 patients who were divided randomly into group I which was immediate implant group (42 patients) and group II which was delayed implant group (42 patients). There were 22 males and 20 females in group I and 18 males and 24 females in group II. We found that mean peri-implant esthetic score at first week in group I was 7.4 and in group II was 5.8, at first month in group I was 6.8 and in group II was 4.6, at third month in group I was 6.7 and in group II was 4.5 and at sixth month in group I was 6.4 and in group II was 4.4. There was significant dissimilarity between both the groups ( $p$ value $<0.05$ ). Edward et al. $^{12}$ in their study compared immediate and delayed implant and factors such as implant esthetic score, crestal bone defect, and densitometry of peri-implant were compared which were recorded after 1 week, 1 month, 3 months, and 6 months in 100 implant sites in 77 patients. Results showed significant difference in implant esthetic score and peri-implant bone densitometry, whereas a nonsignificant difference was found in peri-implant crestal bone loss between both groups ( $p$ value $>0.05$ ) similar to our findings.

We observed that there was nonsignificant mean peri-implant crestal bone loss between both the groups. At 1 week, 1 month, 3 months, and 6 months in group I ( $\mathrm{mm})$ was $0.24,0.64,0.86$, and 1.04 and in group II was $0.28,0.70,0.94$, and 1.14 , respectively. Block et al. ${ }^{13}$ found fewer recession in instant implants ( 26 cases) than in delayed implants ( 29 cases); this is in favor to our findings. However, our results are in contrast to the results of Lindeboom et al. ${ }^{14}$ who found no significant dissimilarity among the peri-implant soft tissue recession in instant and delayed implants in 25 patients each.
We found that mean peri-implant bone densitometry (gray scale assessment) at first week was 52.4 , first month was 45.6 , third month was 42.4, and sixth month was 40.2 in group I and 64.2, 60.5, 55.2 , and 47.6 in group II, respectively. The dissimilarity between both groups was significant ( $p$ value $<0.05$ ). Palattella et al. ${ }^{15}$ included 16 patients aged 21-49 years which were divided into immediate restoration of single tooth over immediate replacement in the esthetic zone. There was nonsignificant difference in marginal bone loss, papilla index, and position of the mucosal margin.

Schropp et al. ${ }^{16}$ compared outcome of immediate and delayed implants in 46 patients placed in incisor, canine, or premolar region of the maxilla or the mandible. The mean reductions in parallel width was from 4.4 to $2.3 \mathrm{~mm}$ (48\%), perpendicular width from 2.2 to $0.9 \mathrm{~mm}(59 \%)$, and depth of the largest defect of each implant from 6.9 to $3.6 \mathrm{~mm}(48 \%)$ in immediate group. In delayed group, it was $39 \%$ (from 3.1 to $1.9 \mathrm{~mm}$ ), $77 \%$ (from 1.3 to $0.3 \mathrm{~mm}$ ), and $34 \%$ (from 4.4 to $2.9 \mathrm{~mm}$ ), respectively. There was significant reduction in immediate group than delayed group.

Paolantonio et al. ${ }^{17}$ found no difference in osseointegration in implants positioned concurrently in immediate extraction sockets and that in mature bone. Recent studies have shown that there is less bone resorption in immediate implant than delayed implants. This procedure allocate an improved final healing because it encourages morphological ridge contour preservation, precise installation of implant, and natural tooth angle maintainance. ${ }^{18-20}$

The shortcoming of the present study is small sample size. Only esthetic zone was taken into consideration. Immediate implants can be used to improve esthetic and determined result in healing of peri-implant bone and peri-implant soft tissues.

\section{Conclusion}

Immediate implant placement reduces bone resorption, maintains crestal anatomy, which is essential for esthetic treatment. Thus, immediate implant placement improves esthetic and functional parameters, compared to delayed implants. Favorable results can be seen with immediate implants in healthy individual with healthy bone support conditions. 


\section{References}

1. Wilson Jr TG, Schenk R, Buser D, et al. Implants placed in immediate extraction sites: a report of histologic and histometric analyses of human biopsies. Int J Oral Maxillofac Implants 1998;13(3):333-341.

2. Wilson Jr TG, Carnio J, Schenk R, et al. Immediate implants covered with connective tissue membranes: human biopsies. J Periodontol 2003;74(3):402-409. DOI: 10.1902/jop.2003.74.3.402.

3. Garber DA, Belser UC. Restoration-driven implant placement with restoration-generated site development. Compend Contin Educ Dent 1995;16(8):796, 798-802, 804.

4. Mayfield LJ. Immediate, delayed and late submerged and transmucosal implants. In: Lang NP, Karring T, Lindhe J, ed. Proceedings of the 3rd European Workshop on Periodontology Implant Dentistry. National J Maxillofac Surgery 2007. pp. 54-62.

5. Zitzmann NU, Schärer $P$, Marinello CP. Factors influencing the success of GBR. Smoking, timing of implant placement, implant location, bone quality and provisional restoration. J Clin Periodontol 1999;26(10):673-682. DOI: 10.1034/j.1600-051X.1999.261007.x.

6. Gomez-Roman G, Kruppenbacher M, Weber H, et al. Immediate postextraction implant placement with root-analog stepped implants: surgical procedure and statistical outcome after 6 years. Int J Oral Maxillofac Implants 2001;16(4):503-513.

7. Hämmerle $\mathrm{CH}$, Chen ST, Wilson Jr TG. Consensus statements and recommended clinical procedures regarding the placement of implants in extraction sockets. Int J Oral Maxillofac Implants 2004;19(Suppl):12-25.

8. Smith DE, Zarb GA. Criteria for success of osseointegrated endosseous implants. J Prosthet Dent 1989;62(5):567-572. DOI: 10.1016/00223913(89)90081-4.

9. Albrektsson T, Zarb G, Worthington P, et al. The long-term efficacy of currently used dental implants: a review and proposed criteria of success. Int J Oral Maxillofac Implants 1986;1(1):11-25.

10. Testori T, Bianchi F, Del Fabbro M, et al. Implant esthetic score for evaluating the outcome: immediate loading in the esthetic zone. Pract Proced Aesthet Dent 2005;17(3):123-130.
11. Esposito M, Grusovin MG, PolyzosIP, et al. Timing of implant placement after tooth extraction: immediate, immediate-delayed or delayed implants? A cochrane systematic review. Eur J Oral Implantol 2010;3(3):189-205.

12. Edward J, George JM, Prakash DG. Evaluation of peri-implant soft tissues and hard tissues in titanium implants in immediate and delayed cases: a comparative study. J Dent Implant 2017;7:3-10. DOI: 10.4103/jdi.jdi_1_17.

13. Block M, Finger I, Castellon $\mathrm{P}$, et al. Single tooth immediate provisional restoration of dental implants: technique and early results. J Oral Maxillofac Surg 2004;62(9):1131-1138. DOI: 10.1016/j.joms.2004.05.115.

14. Lindeboom JA, Tjiook Y, Kroon FH. Immediate placement of implants in periapical infected sites: a prospective randomized study in 50 patients. Oral Surg Oral Med Oral Pathol Oral Radiol Endod 2006;101(6):705-710. DOI: 10.1016/j.tripleo.2005.08.022.

15. Palattella P, Torsello F, Cordaro L. Two-year prospective clinical comparison of immediate replacement vs. immediate restoration of single tooth in the esthetic zone. Clin Oral Implants Res 2008;19(11):1148-1153. DOI: 10.1111/j.1600-0501.2008.01578.x.

16. Schropp L, Kostopoulos L, Wenzel A. Bone healing following immediate vs delayed placement of titanium implants into extraction sockets: a prospective clinical study. Int J Oral Maxillofac Implants 2003;18(2):189-199.

17. Paolantonio M, Dolci M, Scarano A, et al. Immediate implantation in fresh extraction sockets. A controlled clinical and histological study in man. J Periodontol 2001;72(11):1560-1571. DOI: 10.1902/ jop.2001.72.11.1560.

18. Grunder U. Immediate functional loading of immediate implants in edentulous arches: 2 years results. Int J Periodont Rest Dent 2001;21(6):545-551.

19. Devlin H, Sloan P. Early bone healing events in the human extraction socket. Int J Oral Maxillofac Surg 2002;31(6):641-645. DOI: 10.1054/ ijom.2002.0292.

20. Karagianes MT, Westerman RE, Hamilton Al, et al. Investigation of long-term performance of porous-metal dental implants in nonhuman primates. J Oral Implantol 1982;10(2):189-207. 